\title{
Transient intubation for surfactant admini- stration in the treatment of respiratory distress syndrome in extremely premature infants
}

\author{
Ji Won Koh, MD', Jong-Wan Kim, PhD², Young Pyo Chang, MD, PhD' \\ ${ }^{1}$ Department of Pediatrics, Dankook University College of Medicine, Cheonan, ${ }^{2}$ Institute of Tissue Regeneration Engineering (ITREN), Dankook University, Cheonan, \\ Korea
}

Purpose: To investigate the effectiveness of transient intubation for surfactant administration and extubated to nasal continuous positive pressure (INSURE) for treatment of respiratory distress syndrome (RDS) and to identify the factors associated with INSURE failure in extremely premature infants.

Methods: Eighty-four infants with gestational age less than 28 weeks treated with surfactant administration for RDS for 8 years were included. Perinatal and neonatal characteristics were retrospectively reviewed, and major pulmonary outcomes such as duration of mechanical ventilation (MV) and bronchopulmonary dysplasia (BPD) plus death at 36-week postmenstrual age (PMA) were compared between INSURE $(n=48)$ and prolonged MV groups $(n=36)$. The factors associated with INSURE failure were determined.

Results: Duration of MV and the occurrence of BPD at 36-week PMA were significantly lower in INSURE group than in prolonged MV group $(P<0.05)$, but BPD plus death at 36-week PMA was not significantly different between the 2 groups. In a multivariate analysis, a reduced duration of $\mathrm{MV}$ was only significantly associated with INSURE ( $P=0.001)$. During the study period, duration of MV significantly decreased over time with an increasing rate of INSURE application $(P<0.05)$, and BPD plus death at 36-week PMA also tended to decrease over time. A low arterial-alveolar oxygen tension ratio (a/AP02 ratio) was a significant predictor for INSURE failure $(P=0.001)$.

Conclusion: INSURE was the noninvasive ventilation strategy in the treatment of RDS to reduce MV duration in extremely premature infants with gestational age less than 28 weeks.

Key words: Respiratory distress syndrome, Pulmonary surfactants, Endotracheal intubation, Mechanical ventilation, Extremely premature infants

\section{Introduction}

Exogenous surfactant replacement for the treatment of respiratory distress syndrome (RDS) and improvement in mechanical ventilation (MV) therapy dramatically reduced the morbidity and mortality of preterm infants. ${ }^{1,2)}$ However, MV itself can induce lung injury and lead to the subsequent occurrence of bronchopulmonary dysplasia (BPD). ${ }^{3,4)}$ Therefore, noninvasive ventilation strategies in the treatment of RDS have been widely recommended and used for many years. ${ }^{5-8)}$ Many studies have suggested that the early application of nasal continuous positive airway pressure (nCPAP) for RDS treatment is effective and can reduce the occurrence of lung injury ${ }^{5-9)}$ Due to an expected synergistic effect, surfactant administration with nCPAP, has been regarded as an ideal non-invasive method for the treatment of RDS.9

The transient intubation for surfactant administration and then extubated to nCPAP
Corresponding author: Young Pyo Chang, MD, $\mathrm{PhD}$

Department of Pediatrics, Dankook University College of Medicine, 119 Dandae-ro, Dongnam-gu, Cheonan 31116, Korea

Tel: +82-41-550-3937

Fax: +82-41-556-0524

E-mail: ychang@dankook.ac.kr

https://orcid.org/0000-0002-5262-6561

Received: 15 January, 2018

Revised: 2 June, 2018

Accepted: 11 June, 2018
Copyright (C) 2018 by The Korean Pediatric Society

This is an open-access article distributed under the terms of the Creative Commons Attribution NonCommercial License (http://creativecommons.org/ licenses/by-nc/4.0/) which permits unrestricted noncommercial use, distribution, and reproduction in any medium, provided the original work is properly cited. 
(INSURE) method has been widely applied as a less invasive method for RDS treatment, because it has been reported in several studies that INSURE can reduce the duration of MV and the incidence of $\mathrm{BPD}^{5,10-13)}$. Dani et al. ${ }^{12)}$ have confirmed that INSURE decreased the duration of MV in infants less than 30-weeks' gestation compared to infants managed with prolonged MV after surfactant administration. Similarly, Reininger et al. ${ }^{13)}$ reported that the INSURE method significantly reduced the need for MV in infants between 29 to 35-weeks gestation with mild-to-moderate RDS. However, the effectiveness of the INSURE method is still debatable due to inconsistent study results, ${ }^{14-16)}$ and the lack of a standardized guideline particularly in extremely premature infants. The failure rate of INSURE has been reported from $9 \%$ to $40 \%{ }^{17-20)}$

Therefore, we intended to investigate the therapeutic effectiveness of the INSURE method for the treatment of RDS in extremely premature infants with a gestational age of less than 28 weeks, with the expectation that this procedure could reduce the duration of MV and the occurrence of BPD plus death at 36-week PMA, and examined the factors associated with INSURE failure.

\section{Materials and methods}

\section{Subjects}

Eighty-nine extremely premature infants with a gestational age of less than 28 weeks who were treated with surfactant in the neonatal intensive care unit (NICU) of Dankook University Hospital between January 2008 and December 2015 were included. Five infants with congenital anomalies, congenital infection, early death due to severe asphyxia despite extensive resuscitation were excluded. Among the remaining 84 infants, 48 infants (57.1\%) were extubated to nCPAP after the administration of surfactant (INSURE group), and 36 infants (42.9\%) were treated with prolonged MV after the administration of surfactant (prolonged MV group) (Fig. 1). The perinatal and neonatal characteristics and short-term pulmonary

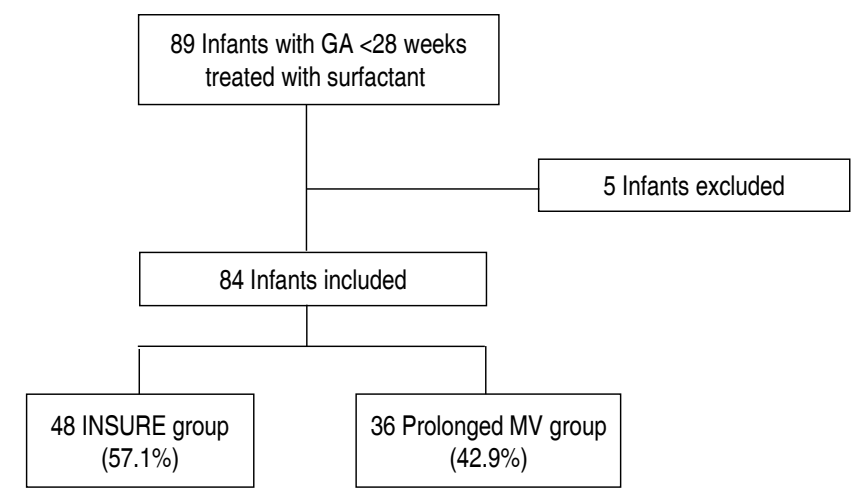

Fig. 1. Study population. GA, gestational age; INSURE, intubation, surfactant administration, and extubated to nCPAP; nCPAP, nasal continuous positive pressure ventilation; MV, mechanical ventilation. outcomes during admission were retrospectively reviewed and compared between the 2 groups. This study was approved by the institutional review board of Dankook University Hospital (IRB No.2015-01-009-001).

\section{Strategies of surfactant administration}

We defined the INSURE method for RDS treatment as transient intubation for surfactant administration, then extubated to nCPAP within 1 hour, based on a previous study. ${ }^{16)}$ Therefore, infants who were able to be extubated to nCPAP within 1 hour after surfactant administration were classified as the INSURE group, and other infants who were treated with MV longer than 1 hour after surfactant administration were classified as the prolonged MV group. In our NICU, the INSURE method has been gradually applied for treatment of RDS since 2008. However, INSURE was applied only for infants with a gestational age over 28 weeks in the first 2 years (2008 to 2009). Thereafter, its application has gradually extended to extremely premature infants with a gestational age of less than 28 weeks. Therefore, the prolonged MV group included the premature infants with a gestational age of less than 28 weeks treated with prolonged MV after surfactant administration during the first 2 years since the application of INSURE. INSURE success was defined as no reintubation within 72 hours after extubation to nCPAP, and INSURE failure was defined as reintubation within 72 hours after extubation. Reintubation after INSURE was considered in infants who met one of the following criteria: $\mathrm{FiO}_{2}$ more than 0.4 with at least 30 minutes of nCPAP to maintain oxygen saturation between $85 \%$ to $92 \%$, respiratory acidosis defined as $\mathrm{pH}<7.20$ and $\mathrm{PaCO}_{2}>65$ $\mathrm{mmHg}$ on arterial or capillary blood gas, or frequent apnea (more than 4 episodes of apnea per hour or more than 2 episodes of apnea per hour when ventilation with bag and mask was required). ${ }^{14)}$ In infants less than 28 weeks of gestation, prophylactic surfactant administration was preferentially considered at the place of delivery, and rescue administration of surfactant was performed in cases where prophylactic administration was not available. The rescue administration of surfactant was performed if the chest radiography showed a typical RDS pattern and infants needed $\mathrm{FiO}_{2}$ of 0.3 or more to maintain $80 \%$ oxygen saturation, and the administration of surfactants was done within 2 hours after birth in most infants. Two kinds of surfactant, Curosurf (Chiesi Pharmaceuticals, Parma, Italy) or Surfacten (Tokyo Tanabe Co., Japan) were randomly used without any preference criteria.

\section{Pulmonary and neonatal outcomes}

The duration of MV and BPD plus death at 36-week PMA were compared between the INSURE and prolonged MV groups as major pulmonary outcomes. Other variables related to pulmonary outcomes such as durations of nCPAP and oxygen supplement, oxygen dependency at 28 days old, BPD at 36-week PMA and postnatal steroid use for BPD were compared between the 2 groups. 
The changes in major pulmonary outcomes over time according to the changing rate of INSURE application during the study period were also evaluated.

Gestational age, birth weight, sex, 1- and 5-minute Apgar scores, and other perinatal factors associated with pregnancy and delivery were evaluated. Clinical or laboratory findings of enrolled infants such as body temperature and mean blood pressure (MBP) at admission, initial lactate and base deficit were evaluated and compared between the INSURE and prolonged MV group. An initial or presurfactant arterial-alveolar oxygen tension ratio $\left(\mathrm{a} / \mathrm{APO}_{2}\right.$ ratio) for infant with prophylactic or rescue treatment of surfactant were evaluated. a/ $/ \mathrm{APO}_{2}$ ratio $\left(\mathrm{PaO}_{2} / \mathrm{PAO}_{2}\right)$ is known as an index of gas exchange function and the $\mathrm{PAO}_{2}$ was defined as follows; ( $\mathrm{PB}-$ $\left.\mathrm{PH}_{2} \mathrm{O}\right) \times \mathrm{FiO}_{2}-\mathrm{PaCO}_{2} \times\left[\mathrm{FiO}_{2}+\left(1-\mathrm{FiO}_{2}\right) / \mathrm{R}\right]$ where $\mathrm{PB}$ is the barometric pressure $\left(760 \mathrm{mmHg}\right.$ ), $\mathrm{PH}_{2} \mathrm{O}$ is the patient's water vapour pressure (47 $\mathrm{mmHg}$ ), $\mathrm{PaCO}_{2}$ is the arterial $\mathrm{CO}_{2}$ tension ( $40 \mathrm{mmHg}$ ) and $\mathrm{R}$ is the gas exchange ratio (0.8). ${ }^{211}$

Additionally, neonatal outcomes such as patent ductus arteriosus (PDA), pulmonary hemorrhage, intraventricular hemorrhage (IVH >grade 2), periventricular leukomalacia, necrotizing of enterocolitis (NEC) or focal intestinal perforation (FIP), retinopathy of prematurity (>grade 2) and culture proven sepsis were compared between the INSURE and prolonged MV groups. BPD was defined as the need for any supplemental oxygen at 36-week PMA, in which mild BPD was excluded according to BPD classification. ${ }^{22)}$

\section{Predictors for INSURE failure}

To evaluate the risk factors to predict INSURE failure, the above clinical and laboratory factors presumed to be related with INSURE failure were compared between the INSURE success and failure group.

\section{Statistical analysis}

Data were analyzed using IBM SPSS Statistics ver. 23.0 (IBM Co., Armonk, NY, USA). Chi-square test, Fisher exact test, Student $t$ test, Mann-Whitney $U$ test, and analysis of variance were used for analyses. $P$ values less than 0.05 were considered significant. To determine whether INSURE might independently affect major pulmonary outcomes, multiple linear regression and logistic regression were performed only on the significant variables in the univariate analysis. The risk factors associated with INSURE failure were analyzed.

\section{Results}

\section{Clinical characteristics}

Mean gestational ages and mean birth weight were not significantly different between the INSURE and prolonged MV groups (26.6 \pm 0.9 weeks vs. $26.3 \pm 1.1$ weeks and $962.9 \pm 162.3 \mathrm{~g}$ vs. $916.3 \pm$
$182.5 \mathrm{~g}$, respectively, $P>0.05)$. One- and 5-minute Apgar scores were significantly lower in the prolonged MV group than in the INSURE group (4.2 \pm 1.6 vs. $5.4 \pm 1.6$ and $6.6 \pm 1.6$ vs. 7.6 \pm 1.0 , respectively, $P<$ $0.05)$. The MBP at admission was significantly lower and lactate level was higher in the prolonged MV group than in the INSURE group $(P<0.05)$. The mean a/ $\mathrm{APO}_{2}$ ratio in the INSURE group was significantly higher than in the prolonged MV group $(0.37 \pm 0.18$ vs. $0.18 \pm 0.15, P=0.000$ ). Male sex was dominant in the INSURE group, and more cesarean section were done in this group. There was a tendency of more antenatal steroid use in the INSURE group (Table 1).

\section{Pulmonary and neonatal outcomes}

The mean duration of MV was significantly shorter in the INSURE group than in the prolonged MV group $(9.9 \pm 15.9$ days vs. 27.8 \pm 21.6 days, $P=0.000$ ), and the rate of BPD at 36-week PMA was significantly lower in the INSURE group than in the prolonged MV group (8.3\% vs. $27.8 \%, P=0.021)$. However, the rate of BPD plus death at 36-week PMA was not significantly different between the two groups ( $29.2 \%$ vs. $44.4 \%, P=0.148$ ). Additionally, infants treated with INSURE had a shorter duration of oxygen supplement $(P=0.045)$, and were less dependent on oxygen at 28 days after birth

Table 1. Clinical characteristics of enrolled infants

\begin{tabular}{lccc}
\hline Characteristic & $\begin{array}{c}\text { INSURE } \\
(\mathrm{n}=48)\end{array}$ & $\begin{array}{c}\text { Prolonged MV } \\
(\mathrm{n}=36)\end{array}$ & $P$ value \\
\hline Gestational age $(\mathrm{wk})$ & $26.6 \pm 0.9$ & $26.3 \pm 1.1$ & 0.174 \\
Birth weight $(\mathrm{g})$ & $962.9 \pm 162.3$ & $916.3 \pm 182.5$ & 0.221 \\
Apgar score & & & \\
$\quad$ 1 Minute & $5.4 \pm 1.6$ & $4.2 \pm 1.6$ & 0.001 \\
$\quad$ 5 Minutes & $7.6 \pm 1.0$ & $6.6 \pm 1.6$ & 0.001 \\
BT at admission ( $\left.{ }^{\circ} \mathrm{C}\right)$ & $36.1 \pm 0.6$ & $34.5 \pm 5.4$ & 0.091 \\
MBP at admission $(\mathrm{mmHg})$ & $34.5 \pm 7.4$ & $29.3 \pm 6.6$ & 0.001 \\
Lactate (mg/dL) & $9.1 \pm 15.0$ & $20.6 \pm 21.6$ & 0.013 \\
Base deficit (mEq/L) & $6.1 \pm 3.6$ & $7.2 \pm 4.1$ & 0.231 \\
a/APO ${ }_{2}$ ratio & $0.37 \pm 0.18$ & $0.18 \pm 0.15$ & 0.000 \\
Male sex & $30(62.5)$ & $14(38.9)$ & 0.032 \\
Cesarean section & $39(81.3)$ & $22(61.1)$ & 0.041 \\
Breech & $7(14.6)$ & $9(25.0)$ & 0.229 \\
Twin & $14(29.2)$ & $11(30.6)$ & 0.890 \\
Antenatal steroid & $35(72.9)$ & $19(52.8)$ & 0.057 \\
SGA & $5(10.4)$ & $3(8.3)$ & 0.748 \\
PROM >18 hours & $19(39.6)$ & $9(25.0)$ & 0.161 \\
Preeclampsia & $1(2.1)$ & $4(11.1)$ & 0.084 \\
Diabetic mother & $1(2.1)$ & $1(2.8)$ & 0.836 \\
\hline Vaus & & &
\end{tabular}

Values are preseted as mean \pm standard deviation or number (\%).

INSURE, intubation, surfactant administration, and extubated to nasal continuous airway pressure (nCPAP); MV, mechanical ventilation; BT, body temperature; MBP, mean blood pressure; a/AP02 ratio, arterial-alveolar oxygen tension ratio; SGA, small for gestational age; PROM, premature rupture of membrane. 
$(P=0.038)$. The postnatal use of steroids for BPD was more common in the prolonged MV group $(P=0.019)$ and surfactants were more commonly administered prophylactically in the INSURE group $(P=$ 0.000). Other neonatal complications were not significantly different between the 2 groups. The rate of INSURE failure was 43.8\% (Table 2).

Multivariate analysis for duration of MV was performed only on the significant variables in the univariate analysis. In a multiple regression analysis, INSURE was only significantly associated with the decreasing duration of MV ( $\beta \pm$ standard error [SE], $-13.00 \pm 3.93$, $P=0.001$ ) (Table 3 ) but not associated with the occurrences of BPD and BPD plus death at 36-week PMA. PDA was also significantly

Table 2. Pulmonary and neonatal outcomes in the INSURE and prolonged MV groups

\begin{tabular}{lccr}
\hline Variable & $\begin{array}{c}\text { INSURE } \\
(\mathrm{n}=48)\end{array}$ & $\begin{array}{c}\text { Prolonged MV } \\
(\mathrm{n}=36)\end{array}$ & P value \\
\hline Duration of MV (day) & $9.9 \pm 15.9$ & $27.8 \pm 21.6$ & 0.000 \\
Duration of nCPAP (day) & $14.4 \pm 13.1$ & $14.0 \pm 13.2$ & 0.898 \\
Duration of oxygen (day) & $3.3 \pm 5.6$ & $6.7 \pm 7.6$ & 0.045 \\
Oxygen at 28 days & $15(31.3)$ & $20(55.6)$ & 0.038 \\
BPD at 36-week PMA & $4(8.3)$ & $10(27.8)$ & 0.021 \\
BPD plus death at 36-week PMA & $14(29.2)$ & $16(44.4)$ & 0.148 \\
Postnatal steroid for BPD & $1(2.1)$ & $6(16.7)$ & 0.019 \\
Prophylactic surfactant & $45(93.8)$ & $10(27.8)$ & 0.000 \\
PDA & $26(54.2)$ & $25(69.4)$ & 0.156 \\
Pulmonary hemorrhage & $1(2.1)$ & $1(2.8)$ & 0.836 \\
IVH> grade 2 & $8(16.7)$ & $4(11.1)$ & 0.471 \\
PVL & $1(2.1)$ & $1(2.8)$ & 0.836 \\
NEC/FIP & $3(6.3)$ & $0(0.0)$ & 0.127 \\
ROP $>$ grade 2 & $6(12.5)$ & $2(5.6)$ & 0.541 \\
Sepsis & $3(6.3)$ & $7(19.4)$ & 0.065 \\
INSURE failure & $21(43.8)$ & - & - \\
\hline
\end{tabular}

Values are presented as mean \pm standard deviation or number (\%).

INSURE, intubation, surfactant administration, and extubated to nCPAP; MV, mechanical ventilation; nCPAP, nasal continuous positive pressure ventilation; BPD, bronchopulmonary dysplasia; PMA, postmenstrual age; PDA, patent ductus arteriosus; IVH, intraventricular hemorrhage; PVL, periventricular leukomalacia; NEC, necrotizing enterocolitis; FIP, focal intestinal perforation; ROP, retinopathy of prematurity.

Table 3. Multiple regression for duration of mechanical ventilation

\begin{tabular}{lrc}
\hline Variable & \multicolumn{1}{c}{$\beta \pm$ SE } & $P$ value \\
\hline INSURE & $-13.00 \pm 3.93$ & 0.001 \\
Gestational age & $-3.21 \pm 2.07$ & 0.124 \\
BT at admission & $-0.2 \pm 0.52$ & 0.708 \\
PDA & $13.62 \pm 3.95$ & 0.001 \\
IVH $>$ grade 2 & $-3.6 \pm 5.54$ & 0.518 \\
\hline
\end{tabular}

SE, standard error; INSURE, intubation, surfactant administration, and extubated to nCPAP; nCPAP, nasal continuous positive pressure ventilation; $\mathrm{BT}$, body temperature; PDA, patent ductus arteriosus; IVH, intraventricular hemorrhage. associated with the increased duration of MV $(\beta \pm \mathrm{SE}, 13.62 \pm 3.95, P=$ 0.001) (Table 3).

During the study period, the duration of MV decreased significantly with the increasing rate of INSURE application $(P<0.05)$. The rate of BPD plus death at 36-week PMA also tended to decrease over time (Fig. 2).

\section{Risk factors for INSURE failure}

The $\mathrm{a} / \mathrm{APO}_{2}$ ratio was a significant risk factor for INSURE failure $(P=0.000)$. IVH $>$ grade 2 and NEC/FIP were also associated with INSURE failure (Table 4). The area under the curve (AUC) of receiver operating characteristic (ROC) curve for the a/ $\mathrm{APO}_{2}$ ratio was 0.80 (95\% CI, 0.68-0.92; $P=0.000)$ and the cutoff value of the $\mathrm{a} / \mathrm{APO}_{2}$ ratio for INSURE failure prediction was estimated at 0.31 with $70.4 \%$ sensitivity and 71.4\% specificity (Fig. 3).

\section{Discussion}

Noninvasive ventilation is now preferentially recommended in various studies to treat preterm neonate with RDS to reduce lung injury. Even for extremely premature infants, nCPAP is recommended as an alternative to intubation in patients who meet specific criteria. $^{23-25)}$ In a recent review from European consensus guidelines, it is strongly recommended that nCPAP be initiated from the beginning of treatment in all infants with RDS, including even those with less than 30 weeks of gestation who do not need intubation. This review also mentioned that the INSURE technique can be applied to infants who are failing on nCPAP. ${ }^{5}$

Several previous studies have reported the validity of the appli-

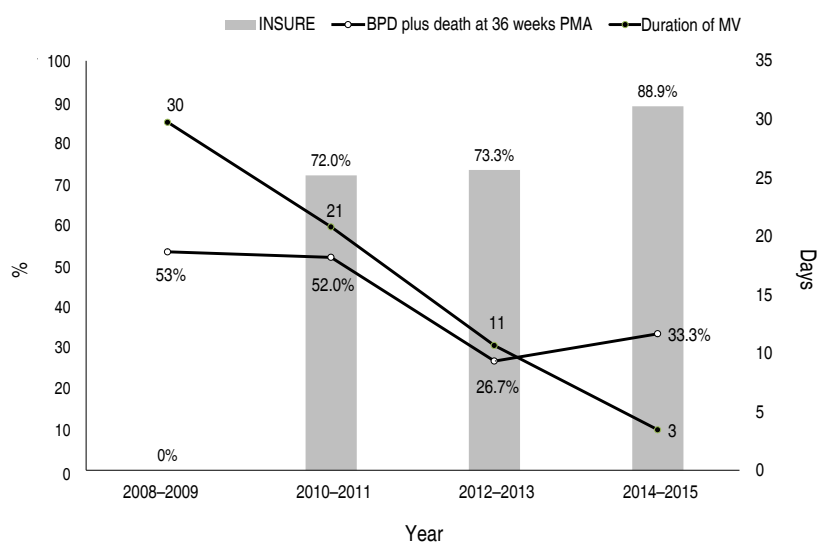

Fig. 2. Changes in major pulmonary outcomes over time during the study period. The duration of mechanical ventilation (MV) decreased significantly with the increasing rate of INSURE application $(P<0.05)$. The rate of BPD plus death at 36-week postmenstrual age (PMA) also tended to decrease over time. INSURE, intubation, surfactant administration, and extubated to nCPAP; nCPAP, nasal continuous positive pressure ventilation; BPD, bronchopulmonary dysplasia. 


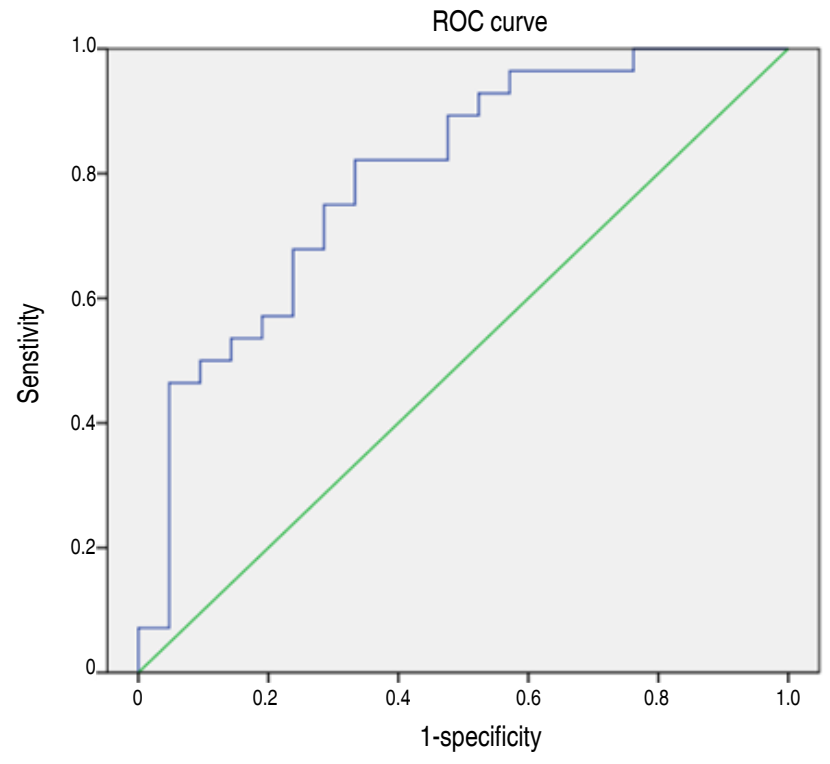

Fig. 3. Receiver operating characteristic (ROC) curve for the arterialalveolar oxygen tension ratio $\left(\mathrm{a} / \mathrm{APO}_{2}\right.$ ratio) for INSURE success prediction. The area under the curve (AUC) was 0.80 (95\% confidence interval, $0.68-0.92 ; P=0.000$ ). The cutoff value of the $\mathrm{a} / \mathrm{APO}_{2}$ ratio for INSURE success prediction was estimated at 0.31 with $70.4 \%$ sensitivity and $71.4 \%$ specificity. INSURE, intubation, surfactant administration, and extubated to nCPAP; nCPAP, nasal continuous positive pressure ventilation; $\mathrm{a} / \mathrm{APO}_{2}$ ratio, arterial-alveolar oxygen tension ratio.

cation of the INSURE method for the treatment of RDS in premature infants. ${ }^{10-13,26-28)}$ In a study including 279 premature infants born at 27- to $31^{+6}$-week gestation with RDS, Rojas et al. ${ }^{27)}$ reported that the need for MV was significantly reduced in the INSURE group compared to the nCPAP group ( $26 \%$ vs. $39 \%, P<0.05)$, and less air-leak and less chronic lung disease was observed in the INSURE group. In another study that included 125 infants with RDS and a gestational age less than 30 weeks, INSURE was effective in 91\% of infants who required a $\mathrm{FiO}_{2}>30 \%$ without need for MV during the first hour of life. ${ }^{28)}$

Similar to the results of previous studies, this study showed that the application of INSURE method for treatment of RDS in extremely premature infants with a gestational age less than 28 weeks reduced the duration of MV and the occurrence of BPD at 36week PMA $(P<0.05)$ but could not reduce the occurrence of BPD plus death at 36-week PMA. Additionally, the duration of oxygen supplement, dependency of oxygen at 28 days and use of a postnatal steroid were significantly decreased in the INSURE group. However, in a multivariate analysis, the reduced duration of MV was only significantly associated with INSURE ( $P=0.001)$, but the occurrences of BPD or BPD plus death at 36-week PMA were not significantly associated with INSURE. PDA was also a significant independent factor for an increase in the duration of MV $(P=0.001)$, presumably because PDA could deteriorate lung function.

The cause of reintubation after INSURE is known to be primarily
Table 4. Predictors of risk factors associated with INSURE failure

\begin{tabular}{|c|c|c|c|}
\hline Variable & $\begin{array}{l}\text { INSURE success } \\
\quad(\mathrm{n}=27)\end{array}$ & $\begin{array}{l}\text { INSURE failure } \\
(n=21)\end{array}$ & $P$ value \\
\hline Gestational age (wk) & $26.7 \pm 0.8$ & $26.4 \pm 1.0$ & 0.225 \\
\hline Birth weight (g) & $950.0 \pm 148.0$ & $934.6 \pm 178.8$ & 0.291 \\
\hline \multicolumn{4}{|l|}{ Apgar score } \\
\hline 1 Minute & $5.8 \pm 1.7$ & $4.9 \pm 1.4$ & 0.063 \\
\hline 5 Minutes & $7.8 \pm 1.0$ & $7.3 \pm 0.8$ & 0.064 \\
\hline BT at admission $\left({ }^{\circ} \mathrm{C}\right)$ & $36.2 \pm 0.6$ & $36.0 \pm 0.7$ & 0.402 \\
\hline MBP at admission (mmHg) & $36.2 \pm 6.9$ & $36.0 \pm 7.7$ & 0.114 \\
\hline Lactate (mg/dL) & $5.9 \pm 7.6$ & $13.2 \pm 21.6$ & 0.152 \\
\hline Base deficit (mEq/L) & $5.3 \pm 2.8$ & $7.2 \pm 4.2$ & 0.065 \\
\hline $\mathrm{FiO}_{2}$ & $0.30 \pm 0.07$ & $0.34 \pm 0.07$ & 0.058 \\
\hline $\mathrm{a} / \mathrm{APO}_{2}$ ratio & $0.45 \pm 0.19$ & $0.28 \pm 0.13$ & 0.001 \\
\hline Male sex & $15(55.6)$ & $15(71.4)$ & 0.260 \\
\hline Cesarean section & $22(81.5)$ & $17(81.0)$ & 0.963 \\
\hline Breech & $2(7.4)$ & $5(23.8)$ & 0.110 \\
\hline Twin & $7(25.9)$ & $7(33.3)$ & 0.575 \\
\hline Antenatal steroid & $21(77.8)$ & $14(66.7)$ & 0.390 \\
\hline SGA & $2(7.4)$ & $3(14.3)$ & 0.439 \\
\hline PROM $>18$ hours & $12(44.4)$ & $7(33.3)$ & 0.435 \\
\hline Preeclampsia & $1(3.7)$ & $0(0)$ & 0.373 \\
\hline Diabetic mother & $0(0)$ & $1(4.8)$ & 0.252 \\
\hline PDA & $15(55.6)$ & $11(52.4)$ & 0.827 \\
\hline IVH $>$ grade 2 & $1(3.7)$ & 7 (33.3) & 0.006 \\
\hline PVL & $1(3.7)$ & $0(0)$ & 0.373 \\
\hline NEC/FIP & $0(0)$ & $3(14.3)$ & 0.043 \\
\hline ROP > grade 2 & $4(14.8)$ & $2(9.5)$ & 0.582 \\
\hline Sepsis & $1(3.7)$ & $2(9.5)$ & 0.409 \\
\hline
\end{tabular}

Values are presented as mean \pm standard deviation or number (\%).

INSURE, intubation, surfactant administration, and extubated to nCPAP; nCPAP, nasal continuous positive pressure ventilation; $\mathrm{BT}$, body temperature; $\mathrm{MBP}$, mean blood pressure; a/ $\mathrm{APO}_{2}$ ratio, arterial-alveolar oxygen tension ratio; SGA, small for gestational age; PROM, premature rupture of membrane; PDA, patent ductus arteriosus; IVH, intraventricular hemorrhage; PVL, periventricular leukomalacia; NEC, necrotizing enterocolitis; FIP, focal intestinal perforation; $\mathrm{ROP}$, retinopathy of prematurity.

related to the severity of RDS. Cherif at al. ${ }^{18)}$ reported that the rate of INSURE failure was 32.1\% in a study of 109 neonates with 2734 weeks of gestation, and the arterial partial pressure of carbon dioxide, mean a/ $\mathrm{APO}_{2}$ ratio and severity of radiological grade for RDS were significantly associated with INSURE failure. Another study reported that the rate of reintubation after INSURE application for RDS was 30\% in newborn infants with a gestational age less than 30 weeks and a birth weight less than $750 \mathrm{~g}$, and RDS severity could affect the success rate of INSURE in a multivariate analysis..$^{19)}$ In a recent study, Najafian et al. ${ }^{20}$ suggested that birth weight was the only predicting factor for the INUSURE success. In this study, INSURE failure rate was $43.8 \%$, which was higher than the results of other studies, presumably because this study mainly included 
extremely premature infants less than 28 weeks of gestation. An initial or presurfactant low $\mathrm{a} / \mathrm{APO}_{2}$ ratio was a significant risk factor for INSURE failure, which suggested that INSURE was more likely to fail if gas exchange in the alveoli was severely impaired due to severe RDS. IVH>grade 2 and NEC/FIP were also significant factors associated with INSURE failure. But, because their numbers were few and they were thought to mainly reflect the progression after application of INSURE, these factors were not considered as main risk factors associated with INSURE failure. The estimated cutoff value of presurfactant $\mathrm{a} / \mathrm{APO}_{2}$ ratio in the ROC curve was 0.31 , which might be a predictive marker for the INSURE failure.

In this study, INSURE was not used for extremely premature infants with a gestational age of less than 28 weeks during 20082009 , but there has been a gradual increase in the rate of extremely premature infants treated by INSURE from 2010 to 2015. During this period, the duration of MV was markedly reduced, and the rates of BPD plus death at 36-week PMA was tended to decrease over time. However, this tendency of decrement in BPD plus death at 36week PMA could not be completely explained by INSURE, because the pathogenesis of BPD is multifactorial and the improvement of the other risk factors associated with the development of BPD during the study period was also thought to be related.

In this study, infants in prolonged MV group had lower 1- and 5-minute Apgar scores, lower MBP, a tendency of less antenatal steroid, a lower $\mathrm{a} / \mathrm{APO}_{2}$ ratio, and a higher level of lactate than infants in the INSURE group, which suggested the possibility that INSURE might be primarily applied to infants with less severe RDS or less severe clinical conditions immediately after birth, and more severe cases might be included in the prolonged MV group. Thus, this baseline discrepancy of the clinical and laboratory characteristics between the 2 groups could affect the differences in pulmonary outcomes between the INSURE and prolonged MV groups. Nevertheless, INSURE in this study was significantly associated with the reduced duration of MV (in a multivariate analysis after adjustment for significant variables in a univariate analysis). In addition, the absence of INSURE use in extremely premature infants in the first 2 years of the study period and a lack of clear guidelines for patient selection and the application of INSURE might affect the results.

There are many ongoing studies to find the best strategy of surfactant administration for the treatment of RDS in preterm neonates. Minimally invasive surfactant therapy (MIST) and similar approaches, called less invasive surfactant administration, are studied as alternative ways to reduce the duration of MV and the incidence of BPD. ${ }^{29-31)}$ Compared directly with the INSURE group, MIST has shown more promising pulmonary outcomes in one study, ${ }^{32)}$ however, there is still controversy surrounding the effectiveness. ${ }^{33)}$

In conclusion, this study suggested that INSURE application for the treatment of RDS in extremely premature infants with gestational age less than 28 weeks might reduce the duration of MV but not the occurrence of BPD plus death at 36-week PMA. An initial or presurfactant low a/APO 2 ratio was a significant risk factor for INSURE failure, which suggested that INSURE was more likely to fail in infants if gas exchange in the alveoli was severely impaired due to severe RDS. A prospective randomized study with more patients is needed to determine the potential benefits of the INSURE strategy for the treatment of RDS and to establish evidence-based guidelines for the INSURE method.

\section{Conflicts of interest}

No potential conflict of interest relevant to this article were reported.

\section{References}

1. Rodriguez RJ. Management of respiratory distress syndrome: an update. Respir Care 2003;48:279-86.

2. Henderson-Smart DJ, Wilkinson A, Raynes-Greenow CH. Mechanical ventilation for newborn infants with respiratory failure due to pulmonary disease. Cochrane Database Syst Rev 2002;(4):CD002770.

3. Hayes D Jr, Feola DJ, Murphy BS, Shook LA, Ballard HO. Pathogenesis of bronchopulmonary dysplasia. Respiration 2010;79:425-36.

4. Gien J, Kinsella JP. Pathogenesis and treatment of bronchopulmonary dysplasia. Curr Opin Pediatr 2011;23:305-13.

5. Sweet DG, Carnielli V, Greisen G, Hallman M, Ozek E, Plavka R, et al. European Consensus Guidelines on the Management of Respiratory Distress Syndrome - 2016 Update. Neonatology 2017;111:107-25.

6. Blennow M, Bohlin K. Surfactant and noninvasive ventilation. Neonatology 2015;107:330-6.

7. Avery ME, Tooley WH, Keller JB, Hurd SS, Bryan MH, Cotton RB, et al. Is chronic lung disease in low birth weight infants preventable? A survey of eight centers. Pediatrics 1987;79:26-30.

8. Cummings JJ, Polin RA; Committee on Fetus and Newborn, American Academy of Pediatrics. Noninvasive respiratory support. Pediatrics 2016;137(1). https://doi.org/10.1542/peds.2015-3758.

9. Verder H, Robertson B, Greisen G, Ebbesen F, Albertsen P, Lundstrøm $\mathrm{K}$, et al. Surfactant therapy and nasal continuous positive airway pressure for newborns with respiratory distress syndrome. DanishSwedish Multicenter Study Group. N Engl J Med 1994;331:1051-5.

10. Stevens TP, Harrington EW, Blennow M, Soll RF. Early surfactant administration with brief ventilation vs. selective surfactant and continued mechanical ventilation for preterm infants with or at risk for respiratory distress syndrome. Cochrane Database Syst Rev 2007;(4): CD003063.

11. Bohlin K, Gudmundsdottir T, Katz-Salamon M, Jonsson B, Blennow M. Implementation of surfactant treatment during continuous positive airway pressure. J Perinatol 2007;27:422-7.

12. Dani C, Bertini G, Pezzati M, Cecchi A, Caviglioli C, Rubaltelli FF. Early extubation and nasal continuous positive airway pressure after surfactant treatment for respiratory distress syndrome among preterm infants <30 weeks' gestation. Pediatrics 2004;113:e560-3.

13. Reininger A, Khalak R, Kendig JW, Ryan RM, Stevens TP, Reubens L, et al. Surfactant administration by transient intubation in infants 29 to 35 weeks' gestation with respiratory distress syndrome decreases the likelihood of later mechanical ventilation: a randomized con- 
trolled trial. J Perinatol 2005;25:703-8.

14. Sandri F, Plavka R, Ancora G, Simeoni U, Stranak Z, Martinelli S, et al. Prophylactic or early selective surfactant combined with nCPAP in very preterm infants. Pediatrics 2010;125:e1402-9.

15. Nakhshab M, Tajbakhsh M, Khani S, Farhadi R. Comparison of the effect of surfactant administration during nasal continuous positive airway pressure with that of nasal continuous positive airway pressure alone on complications of respiratory distress syndrome: a randomized controlled study. Pediatr Neonatol 2015;56:88-94.

16. Isayama T, Chai-Adisaksopha C, McDonald SD. Noninvasive ventilation with vs without early surfactant to prevent chronic lung disease in preterm infants: a systematic review and meta-analysis. JAMA Pediatr 2015;169:731-9.

17. Brix N, Sellmer A, Jensen MS, Pedersen LV, Henriksen TB. Predictors for an unsuccessful INtubation-SURfactant-Extubation procedure: a cohort study. BMC Pediatr 2014;14:155.

18. Cherif A, Hachani C, Khrouf N. Risk factors of the failure of surfactant treatment by transient intubation during nasal continuous positive airway pressure in preterm infants. Am J Perinatol 2008;25:647-52.

19. Dani C, Corsini I, Poggi C. Risk factors for intubation-surfactantextubation (INSURE) failure and multiple INSURE strategy in preterm infants. Early Hum Dev 2012;88 Suppl 1:S3-4.

20. Najafian B, Saburi A, Fakhraei SH, Afjeh A, Eghbal F, Noroozian R. Predicting factors of INSURE failure in low birth-weight neonates with respiratory distress syndrome: a logistic regression model. Iran J Neonatol 2014;5:30-4.

21. Doyle DJ. Arterial/alveolar oxygen tension ratio: a critical appraisal. Can Anaesth Soc J 1986;33:471-4.

22. Jobe AH, Bancalari E. Bronchopulmonary dysplasia. Am J Respir Crit Care Med 2001;163:1723-9.

23. Finer NN, Carlo WA, Duara S, Fanaroff AA, Donovan EF, Wright LL, et al. Delivery room continuous positive airway pressure/positive endexpiratory pressure in extremely low birth weight infants: a feasibility trial. Pediatrics 2004;114:651-7.
24. Alallah J. Early CPAP versus surfactant in extremely preterm infants. J Clin Neonatol 2012;1:12-3.

25. SUPPORT Study Group of the Eunice Kennedy Shriver NICHD Neonatal Research Network, Finer NN, Carlo WA, Walsh MC, Rich W, Gantz MG, et al. Early CPAP versus surfactant in extremely preterm infants. N Engl J Med 2010;362:1970-9.

26. Seong IC, Shin YS, Chang YP. Prophylactic administration of surfactant with nasal continuous positive airway pressure in preterm infants with gestational age less than 30 weeks. J Korean Soc Neonatol 2012; 19:253-61.

27. Rojas MA, Lozano JM, Rojas MX, Laughon M, Bose CL, Rondon MA, et al. Very early surfactant without mandatory ventilation in premature infants treated with early continuous positive airway pressure: a randomized, controlled trial. Pediatrics 2009;123:137-42.

28. Dani C, Corsini I, Bertini G, Fontanelli G, Pratesi S, Rubaltelli FF. The INSURE method in preterm infants of less than 30 weeks' gestation. J Matern Fetal Neonatal Med 2010;23:1024-9.

29. Göpel W, Kribs A, Ziegler A, Laux R, Hoehn T, Wieg C, et al. Avoidance of mechanical ventilation by surfactant treatment of spontaneously breathing preterm infants (AMV): an open-label, randomised, controlled trial. Lancet 2011;378:1627-34.

30. Göpel W, Kribs A, Härtel C, Avenarius S, Teig N, Groneck P, et al. Less invasive surfactant administration is associated with improved pulmonary outcomes in spontaneously breathing preterm infants. Acta Paediatr 2015;104:241-6.

31. Dargaville PA, Ali SKM, Jackson HD, Williams C, De Paoli AG. Impact of minimally invasive surfactant therapy in preterm infants at 29-32 weeks gestation. Neonatology 2018;113:7-14.

32. Kanmaz HG, Erdeve O, Canpolat FE, Mutlu B, Dilmen U. Surfactant administration via thin catheter during spontaneous breathing: randomized controlled trial. Pediatrics 2013;131:e502-9.

33. More K, Sakhuja P, Shah PS. Minimally invasive surfactant administration in preterm infants: a meta-narrative review. JAMA Pediatr 2014;168:901-8. 